\title{
Proper respirators use is crucial for protecting both emergency first aid responder and casualty from COVID-19 and airborne-transmitted infections
}

\section{To the Editor}

We read with great interest the paper by Barycka et al. [1] in which the authors argue that healthcare workers (HCWs) should use filtering facepiece masks (FFP) with exhaust valve, when performing procedures such as cardiopulmonary resuscitation (CRP), to reduce the adverse effects of using FFP without valve, including high discomfort, low performance and thermal stress.

Their letter, however, addresses numerous prevention problems and deserves some clarification. The literature agrees on the greater effectiveness of filter masks compared to surgical ones in protecting HCWs against microorganisms; however, it is known that filter masks do not offer absolute safety against coronaviruses and prevention must be based on the simultaneous adoption of many measures [2].

There is also a broad consensus that wearing a mask for the entire work shift during a pandemic can cause numerous symptoms in workers [3]. These problems, whose pathogenesis is due to a combination of ergonomic and psychosocial factors, require a careful choice of this Personal Protective Equipment (PPE), with the participatory contribution of workers, as indicated by the European Directives on health and safety at workplace.

However, we believe that the example chosen by the authors to illustrate their claim is not appropriate. Cardiopulmonary resuscitation (CPR) is not an exclusively hospital procedure, because it must be performed in prehospital setting, including when needed at workplace. In addition, no HCW carries out this activity for the entire work shift. Consequently, extrapolating the conditions of the long-time occupational mask user to the rescuer doing CPR in the workplace can be misleading.

During first aid, indeed, rescuer and casualty come into close contact, especially during CRP. Mouth-to-mouth resuscitation poses, therefore, the greatest risk of COVID-19 infection not only to rescuer, but also to the casualty. For this reason, ERC guidelines suggest that appropriate PPEs, such as gloves, masks and visor eye protection should we worn by rescuers, whereas the casualty should wear surgical mask. FFP masks, furthermore, must be made of filter material, cover the nose and mouth, and possibly also the chin (semi-mask) [4].

It is possible, indeed, that lay or medical first aid responders who are asymptomatic carriers can transmit the SARS-CoV-2 virus to casualty, if they use respirators with EV [5]. It is well known that HCWs are at high risk of infection and can be a source of infection [6, 7]. Asymptomatic or presymptomatic HCWs acting as potential "superspreaders" were cited as responsible of COVID-19 hospital outbreaks [8]. At the same time, casualty can be particularly "vulnerable" to COVID-19 infection [8].

SARS-CoV-2 is a highly contagious virus and facial respirators could be insufficient to prevent the infection, because the "minimal infective dose" of the virus responsible for COVID-19 infection is unknown [4, 9]. Therefore, adverse 
effects in HCWs caused by using respirators without EV should be carefully assessed and balanced with the risk of SARS-CoV-2 transmission to casualty.

In this evaluation, it should be noted that hospital HCWs wearing PPEs against COVID-19 (i.e., masks, respirators, gloves, and in hospitals where the contact with the infected and confirmed patient is direct, also gowns or body covers) can have many troubles to change their mask when it comes to perform lifesaving maneuvers. The level of protection, indeed, depends much on the ability to use the masks correctly, including if the rescuer has passed fit testing [4].

Physical fatigue and discomfort in people performing CRP should be prevented with organizational measures. Rescuers should be encouraged to interchange after 2 minutes of CPR delivery. Team leaders must be instructed to arrange changes in advance, without waiting for rescuers to report fatigue. Early defibrillation, finally, remains the major key to a successful outcome [10].

In conclusion, we believe it is more prudent that in case of emergency, both lay and medical rescuers use respirators without EV, except when hospital HCWs assist patients with highly suspected or confirmed COVID-19 infection. Educational efforts, implementing fit testing and seal checking of masks, organizational measures as well as using appropriate PPEs are needed to offer safe emergency interventions to rescuer and casualty for this and other airborne-transmitted diseases.

\section{Conflict of interest}

None declared.

\section{References:}

1. Barycka K, Dzieciątkowski T, Drozd A, et al. Should emergency medical service stuff use respirators with filtered valve in COVID-19 pandemic? Adv Respir Med. 2020; 88(6): 638-639, doi: 10.5603/ARM.a2020.0167, indexed in Pubmed: 33393663.

2. Puro V, Magnavita N, Ippolito G. SARS and masks. J Hosp Infect. 2004; 56(1): 73-74, doi: 10.1016/i.jhin.2003.09.010, indexed in Pubmed: 14706275.

3. Magnavita N, Chirico F. Headaches, personal protective equipment, and psychosocial factors associated with COVID 19 pandemic. Headache: The Journal of Head and Face Pain. 2020; 60(7): 1444-1445, doi: 10.1111/head.13882.

4. Magnavita N, Sacco A, Nucera G, et al. First aid during the COVID-19 pandemic. Occup Med (Lond). 2020; 70(7): 458-460, doi: 10.1093/occmed/kqaa148, indexed in Pubmed: $\underline{32749455}$.

5. Chirico F, Nucera G, Magnavita N. COVID-19: protecting healthcare workers is a priority. Infect Control Hosp Epidemiol. 2020; 41(9): 1117, doi: 10.1017/ice.2020.148, indexed in Pubmed: $\underline{32299519}$.

6. Chirico F, Magnavita N. The crucial role of occupational health surveillance for health-care workers during the COVID-19 pandemic. Workplace Health Saf. 2021; 69(1): 5-6, doi: 10.1177/2165079920950161, indexed in Pubmed: 32961069.

7. Chirico F, Nucera G. Tribute to healthcare operators threatened by COVID-9 pandemic. J Health Soc Sci. 2020; 5(2): 65-68. Doi: 0. 2020; 5(2): 165-168 Doi: 10 1. 9204; 2020: trbt1, doi: 10.19204/2020/trbt1.

8. Chirico F, Nucera G, Magnavita N. Hospital infection and COVID-19: Do not put all your eggs on the "swab" tests. Infect Control Hosp Epidemiol. 2020 [Epub ahead of print]: 1-2, doi: 10.1017/ice.2020.254, indexed in Pubmed: $\underline{32456750}$.

9. Chirico F, Sacco A, Bragazzi NL, et al. Can air-conditioning systems contribute to the spread of SARS/MERS/COVID-19 infection? Insights from a rapid review of the literature. Int J Environ Res Public Health. 2020; 17(17), doi: 10.3390/ ijerph17176052, indexed in Pubmed: $\underline{32825303}$.

10. McDonald CH, Heggie J, Jones CM, et al. Rescuer fatigue under the 2010 ERC guidelines, and its effect on cardiopulmonary resuscitation (CPR) performance. Emerg Med J. 2013; 30(8) 623-627, doi: 10.1136/emermed-2012-201610, indexed in Pubmed: 22851670 . 